\title{
Bone marrow biopsy and aspiration: a departmental financial comparison in a rural hospital
}

\author{
Nancy W. Bethuel ${ }^{*}$ (D, Eric Bravin, Nicole Krupa, Paul Jenkins, Melissa Scribani and Anne Gadomski
}

\begin{abstract}
Objective: The purpose of this study was to compare the charges and payments associated with bone marrow aspiration and biopsies performed by hematology/oncology specialists versus interventional radiology specialists at Bassett Medical Center located in a rural area of New York State. Charges pertained to what the hospital charged for the procedure and payment refers to the reimbursement the hospital received. Our secondary objectives were to compare specimen quality by procedure and to determine whether body mass index was associated with which specialist performed the procedure.

Results: The median charge was significantly higher in the interventional radiology group (\$5254 USD) compared to the hematology/oncology group (\$413 USD), $p<0.0001$. Median payments were also higher in the interventional radiology (\$1392 USD) compared to the hematology/oncology group (\$1109 USD), $p<0.0001$. Adequacy of the samples obtained by either profession was similar. Disease process was not associated with adequacy of the sample. There was no statistically significant difference in the proportion of males and females in the respective groups or in the mean age. However, the patients' in the interventional radiology group had a significantly higher mean BMI (34.3) compared to those in the hematology/oncology group (28.6), $p=0.0014$.
\end{abstract}

Keywords: Bone marrow biopsy, Bone marrow aspirate, Rural health, Hematology oncology, Interventional radiology

\section{Introduction}

Bone marrow aspiration and biopsies (BMAB) procedures are carried out for cytological assessment of various hematological diseases [1]. Highly specialized testing, such as cytogenetic, immunophenotypic, and molecular analyses, can be performed on these specimens; this information has become critically important in establishing certain diagnoses, especially leukemia and lymphomas.

The procedure is carried out by a trained clinician so that adequate tissue is obtained for evaluation [2]. Biopsies are usually performed on the posterior iliac crest. While patient comfort and safety are important, health

*Correspondence: nancy.bethuel@bassett.org

Bassett Medical Center, One Atwell Road, Cooperstown, NY 13326, USA care related cost is also important especially in rural settings and/or low resource settings.

Over the last few years, we have noted an increasing trend in the number of BMAB procedures performed by interventional radiology (IR) specialists [3] compared to those performed in office by hematology/oncology (HO) specialists. We hypothesized that this cost would be significantly higher in the IR department with no significant difference in procedure success or sample adequacy.

The purpose of this study was to analyze the costs associated with $\mathrm{BMAB}$ performed by $\mathrm{HO}$ compared to IR in our rural health network between April 2017 and March 2019. A secondary objective was to describe the differences in patient characteristics for those whose $B M A B$ was done by IR compared to those that were done by HO.

(c) The Author(s) 2021. This article is licensed under a Creative Commons Attribution 4.0 International License, which permits use, sharing, adaptation, distribution and reproduction in any medium or format, as long as you give appropriate credit to the original author(s) and the source, provide a link to the Creative Commons licence, and indicate if changes were made. The images or other third party material in this article are included in the article's Creative Commons licence, unless indicated otherwise in a credit line to the material. If material is not included in the article's Creative Commons licence and your intended use is not permitted by statutory regulation or exceeds the permitted use, you will need to obtain permission directly from the copyright holder. To view a copy of this licence, visit http://creativecommons.org/licenses/by/4.0/. The Creative Commons Public Domain Dedication waiver (http://creativecommons.org/publicdomain/zero/1.0/) applies to the data made available in this article, unless otherwise stated in a credit line to the data. 


\section{Main text Methods}

All pathology reports for BMAB performed between April 2017 and March 2019 by HO and IR at our institution were retrospectively reviewed by the authors. Because costs cannot be measured directly, we compared two proxies for the health-related costs: 1) charges pertain to how much the patients were charged for the procedure and 2) payments refers to the reimbursement the hospital received.

The study population included inpatients and outpatients. Each procedure was reviewed for age, sex, BMI, diagnosis and adequacy of the sample. Charges associated with each procedure encounter were compiled by our finance department. We merged biopsy data with finance data based on hospital identification number (ID). Medical record numbers (MRNs) with more than one hospital ID (more than one biopsy) were included. One set of duplicate hospital IDs was deleted because there were two records of biopsies on the same contact date; the finance department confirmed that this was a duplicate report. Since we had no way to know which biopsy to assign that cost to, both were deleted. One was in the $\mathrm{HO}$ group and one in the IR group.

Due to large right skew in the distribution of charges and payments, we presented medians and interquartile ranges. For MRNS with multiple biopsies, age, BMI and cost data were averaged and weighted by the number of biopsies per MRN. Comparisons of mean age and mean BMI between the $\mathrm{HO}$ and IR groups were carried out using the student's t-test. The chi-square test was used to compare the percentage of male/female patients between $\mathrm{HO}$ and IR groups.

The non-parametric Wilcoxon Rank Sum test was used to compare median charges and payments between $\mathrm{HO}$ and IR groups. P-values of less than 0.05 were considered statistically significant. The number of procedures performed by $\mathrm{HO}$ and IR groups, respectively, were examined for change over the study period using linear regression analysis. A significant positive slope would indicate an increasing number of procedures, while a significant negative slope would indicate a decreasing number of procedures over time.

This study was deemed exempt from continuing review by the Mary Imogene Bassett Hospital Institutional Review Board.

\section{Results}

There was a total of 270 procedures performed during the study period; 179 and 91 performed by $\mathrm{HO}$ and IR respectively. No immediate complications were reported in either group. Five patients in both groups required repeat procedures to obtain an adequate bone marrow sample. There was no difference in the adequacy of the sample obtained by either method, or no difference in need for repeat procedure. Disease process was not a factor in whether the sample was adequate.

The number of biopsies performed by IR increased significantly over the study period ( $p=0.023$; Fig. 1$)$. In contrast, the number of biopsies done by $\mathrm{HO}$ showed a general, although non-significant $(p=0.09)$, downward trend (Fig. 1).

There was a higher proportion of males in the $\mathrm{HO}$ group (Table 1). However, this difference was not statistically significant. Mean BMI was significantly higher among the IR biopsies; 34.3 compared to $28.6 \mathrm{~kg} / \mathrm{m}^{2}$ in the HO group (Table 1).

Median charges were also significantly higher in the IR group (Table 1), \$5254 USD (interquartile range: (\$4328$\$ 6227)$ compared to $\$ 413$ USD (interquartile range: $\$ 192-\$ 2050)$ in the HO group. Payments were higher for the IR group, with median payments of \$1392 USD compared to $\$ 1109$ USD for the HO group (Table 1). The higher charges for procedures by the IR group were likely attributable to operating and recovery room costs.

\section{Discussion}

We compared the health care related costs of a relatively common procedure when performed by $\mathrm{HO}$ versus IR. Although sample adequacy was the same, median charges and payments were significantly higher when the procedure was performed by IR specialists compared to in office procedures performed by HO specialists.

Our rural community hospital has seen a steady increase in IR procedures which has raised concerns about the costs. We found that over the last two years, more $\mathrm{BMAB}$ are being performed by the IR department with no difference in quality of the specimens. A similar trend has been seen across other parts of the United States [1].

While the World Health Organization recommends a bone marrow length of $>=15 \mathrm{~mm}$ and while operator experience can affect specimen quality [2], we were not able to assess these factors as very few pathology reports commented on the length of the biopsies. The most common reason to repeat a BMAB was an acellular or suboptimal core and dilute or apiculate aspirate. However, in suboptimal samples where the diagnosis was still made, the procedure was not repeated.

Previous studies have reported higher rates of successful and safe BMAB by CT guided biopsy in patients with higher BMIs [3]. This could explain why the IR group of patients have a statistically significant higher mean BMI (Table 1). However, we could not determine by chart review whether our $\mathrm{HO}$ specialists systematically referred patients with higher BMIs to IR. When we presented our 
Key: Blue - Hematology/Oncology, Orange - Interventional Radiology

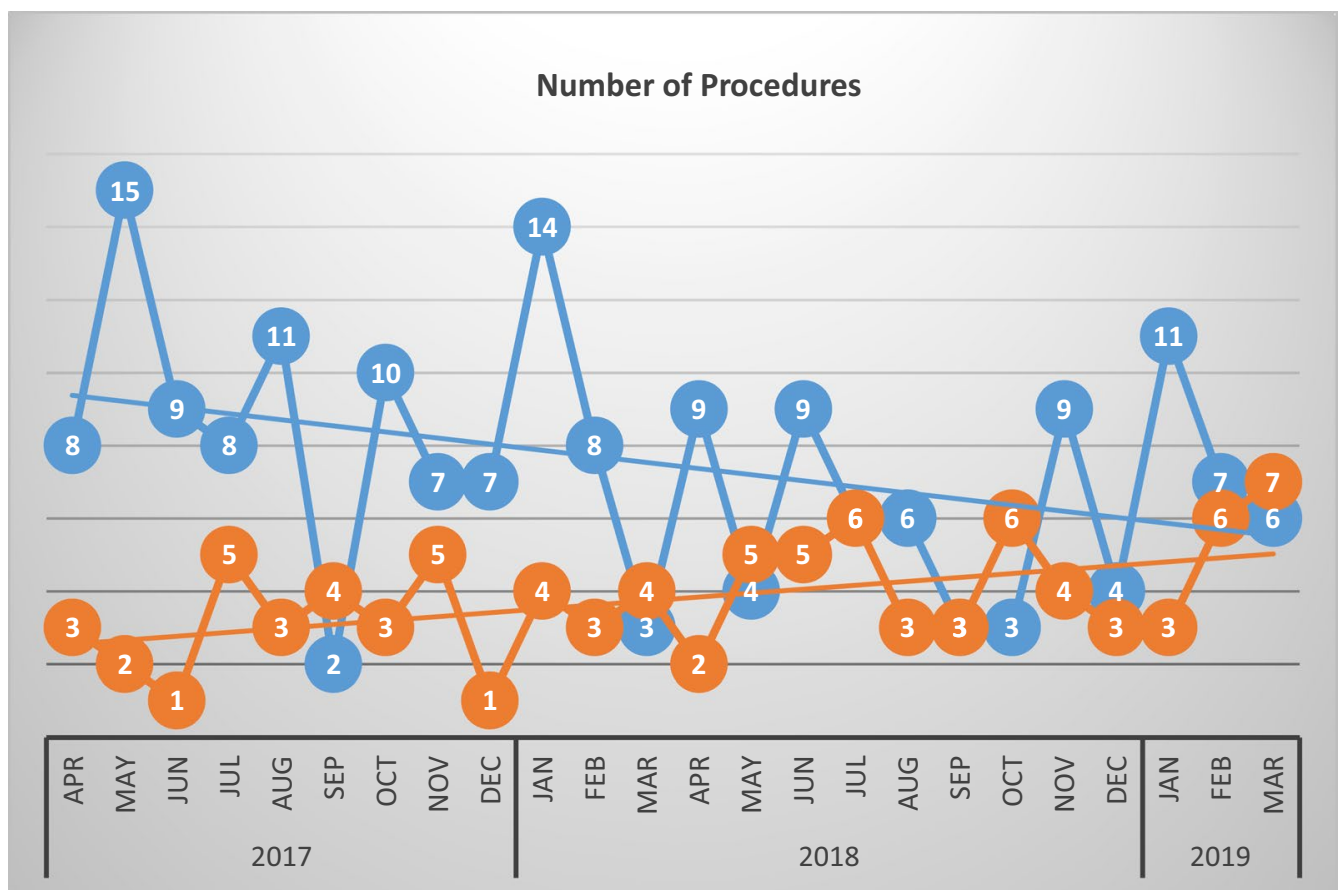

Fig. 1 Number of procedures. Key: Blue-Hematology/Oncology, Orange—Interventional Radiology

Table 1 Patient characteristics

\begin{tabular}{llll}
\hline & HO & IR & $\boldsymbol{p}$ value \\
\hline Mean Age & 66.3 & 65.0 & 0.5127 \\
\% Males & 55.9 & 46.2 & 0.1309 \\
Mean BMl & 28.6 & 34.3 & $<0.0001$ \\
Diagnostic Rate & $97.8 \%$ & $94.5 \%$ & $\mathrm{~N} / \mathrm{a}$ \\
Median Charges & $\$ 413$ & $\$ 5254$ & $<0.0001$ \\
(Interquartile Range) & $(\$ 192-\$ 2050)$ & $(\$ 4328-\$ 6227)$ & \\
Median Payments & $\$ 1109$ & $\$ 1392$ & $<0.0001$ \\
(Interquartile Range) & $(\$ 119-\$ 1408)$ & $(\$ 1122-\$ 3695)$ & \\
\hline
\end{tabular}

results to the HO department, we learned that body habitus makes it difficult to palpate physical landmarks without imaging guidance [3]. A potential alternative to an IR procedure would be, ultrasound guided $B M A B$ that has been shown to be just as effective [4], but less costly than an IR procedure. Further research is needed to demonstrate whether ultrasound guided BMAB is as effective as IR in yielding an adequate sample while incurring less cost. Of note, previous studies have not found difference in diagnostic rate of BMAB performed by IR versus $\mathrm{HO}$ in non-obese patients [4].

The median cost for IR performed BMAB was $\$ 1392$ USD per BMAB compared to \$1109USD per
BMAB performed by $\mathrm{HO}$, yielding an average excess cost of approximately $\$ 283$ USD per BMAB performed by IR. Given similar sample adequacy at a substantially and significantly increased cost, our findings do not support universal performance of IR performed BMAB. CT-guided biopsy also exposes patients to radiation. Having said that, IR performed BMAB could be reserved for patients with body habitus that limits the clinician's ability to palpate important anatomic landmarks [1]. Alternatively, ultrasound guided $\mathrm{BMAB}$ could be used for these patient groups [5], however a comparison of IR guided $\mathrm{BMAB}$ and ultrasound guided $\mathrm{BMAB}$ is needed.

These findings imply that the cost-effectiveness for care of patients with hematologic disorders could be improved. Although sample adequacy was comparable, median charges and payments were significantly higher when the BMAB procedure was performed by an IR specialist compared to in office procedures performed by $\mathrm{HO}$ specialists. Reasons for patient referral to IR may include elevated BMI. Whether ultrasound guided $\mathrm{BMAB}$ can be used as an alternative to the more costly IR procedure is unknown but should be investigated. Further research is also needed regarding a potential cut-off BMI at which patients should be referred to IR. 


\section{Limitations}

The study was performed at a single institution in a rural area, thus limiting its generalizability to urban settings and different patient populations. Given the increasing prevalence of obesity across the United States [6], there will likely be an increasing trend of CT-guided biopsy with IR. This being a retrospective study itself introduces a bias potentially related to the quality of data collected because these data were not planned ahead of time and standardized. Lastly there may be an imbalance of unmeasured factors between the two groups that influenced the type of BMAB procedure they received. These limitations could be resolved in the careful design of prospective studies in the future.

\section{Abbreviations}

BMAB: Bone marrow aspiration and biopsies; IR: Interventional radiology; HO: Hematology/oncology; ID: Hospital identification number; MRN: Medical record numbers.

\section{Acknowledgements}

Thank you to the department chair, Dr Mebust, for his support of this work.

\section{Authors' contributions}

NB contributed to the conception, data acquisition, interpretation, design and drafting of this work. EB contributed to the conception, interpretation and revision of this work. NK assisted in the acquisition and analysis of the data. MS assisted in the analysis and interpretation of the data. PJ contributed to the interpretation and revision of this work. AG contributed to the design, data acquisition, interpretation and revision of this work.

All authors take responsibility for the integrity of the work as a whole, have approved the submitted version and agree both to be personally accountable for the author's own contributions and to ensure that questions related to the accuracy or integrity of any part of the work, even ones in which the author was not personally involved, are appropriately investigated, resolved, and the resolution documented in the literature.

\section{Funding}

This research was supported by the E. Donnall Thomas Resident Research program at the Bassett Research Institute, Bassett Medical Center, Cooperstown, New York.

\section{Availability of data and materials}

The data that support the findings of this study are available on request from the corresponding author, Nancy Bethuel. The data are not publicly available due to their containing information that could compromise the privacy of the research participants.

\section{Ethic's approval and consent to participate}

The Mary Imogene Bassett Hospital Institutional Review Board approved this study. Informed consent was not applicable.

\section{Consent for publication}

As the lead and corresponding author, I confirm that the manuscript has been read and approved for submission by all named authors. We confirm that this paper is not being reviewed for publication by another journal.

\section{Competing interest}

There are no known conflicts of interest associated with this publication and there has been no significant financial support for this work that could have influenced its outcome.

Received: 16 October 2020 Accepted: 16 February 2021

Published online: 04 March 2021

\section{References}

1. Manchec B, Limback J, Liu B, Pepe JW, Burt J, Contreras F, Ward TJ. Safety and technical success of CT-guided bone marrow biopsy in obese patients. J Clin Interv Radiol ISVIR. 2020;4(01):16-9.

2. Marinelli LM, Fang H, Howard MT, Hanson CA, Haack JJ, Eick EA, Allen RJ, Ruffridge DE, Byrne CM, King RL. Bone marrow biopsy operator experience and impact on aspirate, biopsy, and ancillary testing quality. Mayo Clin Proc Innov Qual Outcomes. 2018;2(3):241-7.

3. Ahmed O, Wadhwa V, Patel MV, Patel K, Lionberg A, Klejch W, Lizardo A, Ginsburg M. Increasing volume of bone marrow biopsies by radiology providers: evaluation of trends by physician specialty and practice setting. J Am Coll Radiol. 2020;17(7):933-7.

4. McLaughlin S, Mead L, Clark T, Trerotola S, Dagli M. 04: 03 PM Abstract No. 380 Development of evidence-based guidelines for bone marrow biopsy requests in IR: a retrospective comparison of the outcomes of 2800 biopsies done at the bedside versus under image guidance. J Vasc Interv Radiol 2019; 30(3):S167-8.

5. Raza S, Raza F, Rezaie N, Quiambao J. 04: 12 PM Abstract No. 381 Using ultrasound guidance for bone marrow biopsy in an outpatient office setting. J Vasc Interv Radiol. 2019; 30(3):S168.

6. Lee M. Obesity among US rural adults: Assessing selection and causation with prospective cohort data. Health Place. 2020;1(61):102260.

\section{Publisher's Note}

Springer Nature remains neutral with regard to jurisdictional claims in published maps and institutional affiliations.

Ready to submit your research? Choose BMC and benefit from:

- fast, convenient online submission

- thorough peer review by experienced researchers in your field

- rapid publication on acceptance

- support for research data, including large and complex data types

- gold Open Access which fosters wider collaboration and increased citations

- maximum visibility for your research: over $100 \mathrm{M}$ website views per year

At $\mathrm{BMC}$, research is always in progress.

Learn more biomedcentral.com/submissions 